\title{
Osteoid Osteoma of Cuboid Bone- A Rare Cause of Chronic Foot Pain in Childhood -A Case Report
}

\author{
Sunny Chaudhary ${ }^{\circledR 1}$, V Abdusamad ${ }^{\odot 2}$, Aman Verma ${ }^{\circ 2}$, Varun Garg ${ }^{\oplus 1}$, R K Siddharth ${ }^{\circledR 2}$, Vivek Singh ${ }^{\oplus 3}$ \\ ${ }^{1}$ Senior Resident, Department of Orthopedics, AllMS, Rishikesh, Uttarakhand, India, ${ }^{2}$ Junior Resident, Department of Orthopedics, AllMS, Rishikesh, Uttarakhand, India, \\ ${ }^{3}$ Associate Professor, Department of Orthopedics, AllMS, Rishikesh, Uttarakhand, India.
}

\section{Abstract}

Chronic foot pain in pediatric age group is less common. The usual differential diagnosis may vary from musculoskeletal injury to serious diseases such as osteomyelitis. Benign bone tumor such as osteoid osteoma of foot is exceedingly rare in this age group. Here we present a rare case of osteoid osteoma of cuboid mimicking osteomyelitis. Patient was managed conservatively by Non-steroidal Anti-inflammatory drugs (NSAIDs) with good clinical outcome. Osteoid osteoma of foot bones should be kept in mind in cases with normal blood parameters.

Keywords: Osteoid Osteoma, Cuboid, Pediatric.

Corresponding Author: Vivek Singh, Associate Professor, Department of Orthopedics, AIIMS, Rishikesh, Uttarakhand, India. E-mail: singhvr27@gmail.com

Received: 25 September 2020

Revised: 12 November 2020

Accepted: 22 November 2020

Published: 30 December 2020

\section{Introduction}

Chronic foot pain with swelling in a child can be due to many musculoskeletal and rheumatologic diseases. Broad differential diagnosis must be kept in mind which may vary from benign to serious conditions such as osteomyelitis. Ankle sprain, anterior impingement syndrome, stress fractures, chronic tendinitis and arthritis are more commonly seen. Benign and malignant tumors are rare causes of foot pain. Osteoid osteoma is a benign tumor of bone most commonly occurring in the young adults in the second and third decade of life. ${ }^{[1]}$ It is commonly seen in tibia, femur and spine. It can be rarely seen in bones of the foot and talus is the most commonly affected. ${ }^{[2]}$ The male to female preponderance is $3: 1 .^{[3]}$ Patients usually come with chronic pain with nocturnal aggravation. Pain is generally not associated with trauma. The pain usually responds well to Non-steroidal Antiinflammatory drugs (NSAIDs. Osteoid osteoma of foot bones should be kept in differential diagnosis to prevent unnecessary delay in cases with normal blood parameters.

\section{Case Presentation}

A 9-year-old female presented with complaints of chronic pain of right foot for 1 year and swelling for past 3 months. Pain was insidious in onset, dull in nature, localised to right foot and was not fully relieved on rest and immobilisation. Patient gave a history of worsening of pain at night which progressively increased over a period of 1 year.

Patient also noticed a swelling over the right foot which was insidious in onset and localised on anterolateral part of midfoot. There was no history of fever or any constitutional symptoms. No preceding history of trauma was present.

Patient was initially managed by primary physician who advised a below knee cast and non-weight bearing for 3 weeks. On subsequent follow up patient showed no signs of improvement and hence was referred to our institute for further management.

On examination there was mild local rise of temperature. A diffuse swelling was noted over the lateral aspect of right foot with ill-defined margins. The swelling and was soft to firm in consistency. Skin over the swelling was normal. Ankle and toe movements were normal.

The Erythrocyte Sedimentation Rate (ESR), C-Reactive Protein (CRP) and Total Leucocyte Count (TLC) were in normal range. Plain radiograph of the right foot showed a welldefined lesion in the cuboid bone [Figure 1]. A CT scan of right foot was advised and it was suggestive of Osteoid osteoma of cuboid which was subperiosteally located and measuring $2 \times 1 \mathrm{~cm}$ in size [Figure 2]. Subsequently, MRI was advised which showed diffuse oedema in the medullary cavity of the cuboid bone as well as the surrounding soft tissues. A sub- 


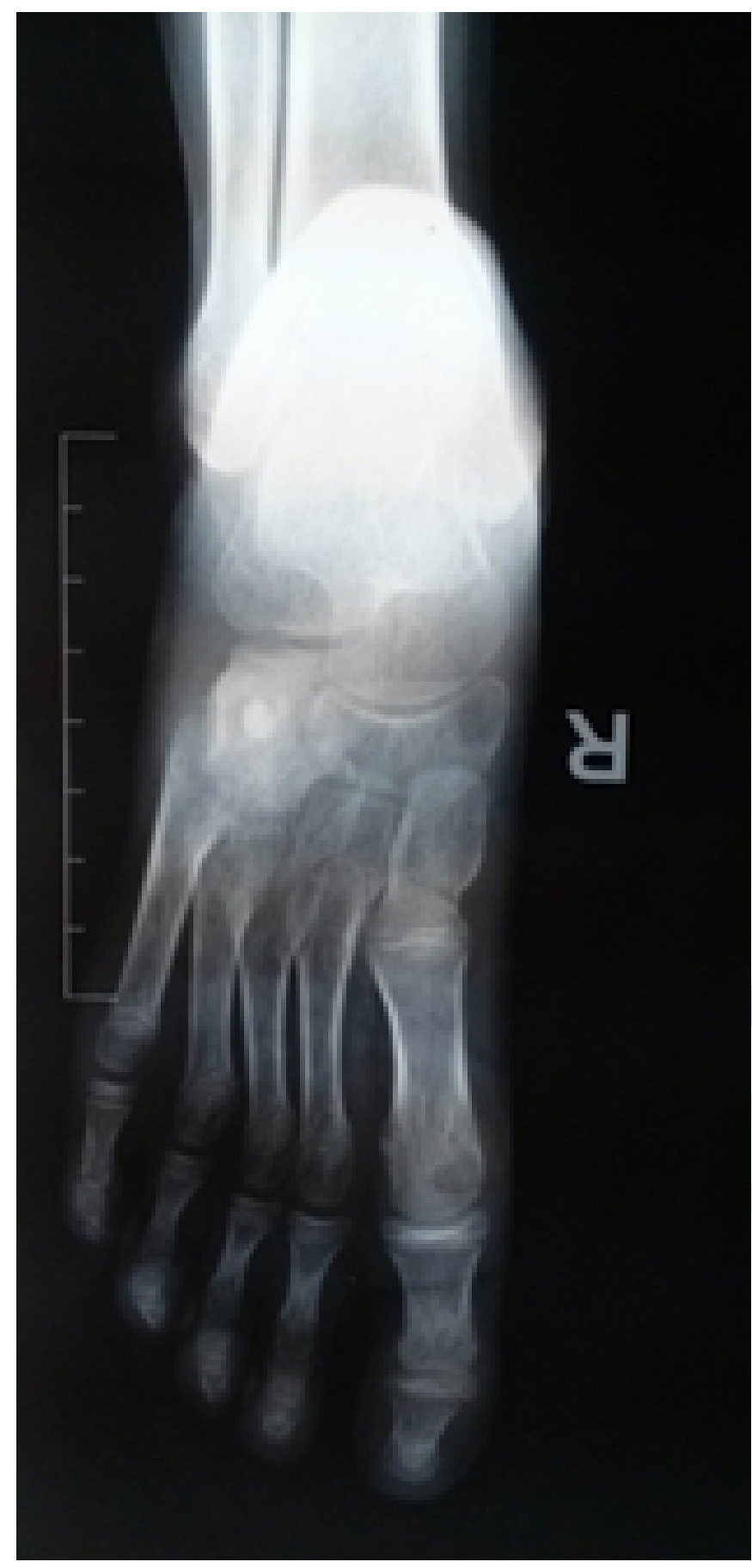

Figure 1: Plain radiograph of the right foot showed a well-defined lesion in the cuboid bone.

periosteally located osteoid osteoma nidus was noted in the cuboid bone [Figure 3, 4]. A differential diagnosis of chronic osteomyelitis and brodie's abscess were kept in mind. No definitive history, normal blood parameters and a radiograph

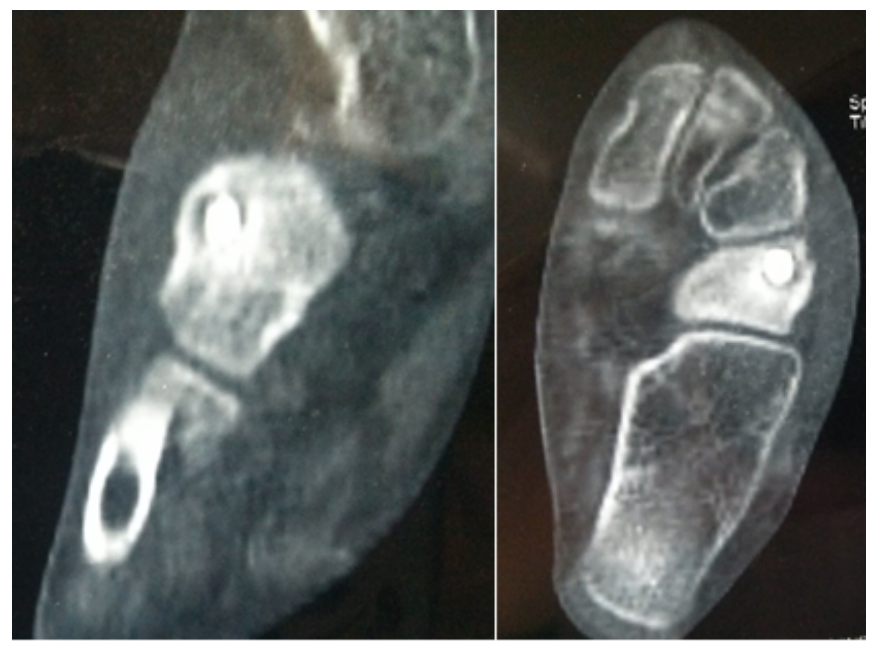

Figure 2: A CT scan of right foot was advised and it was suggestive of Osteoid osteoma of cuboid which was subperiosteally located and measuring $2 \times 1 \mathrm{~cm}$ in size.

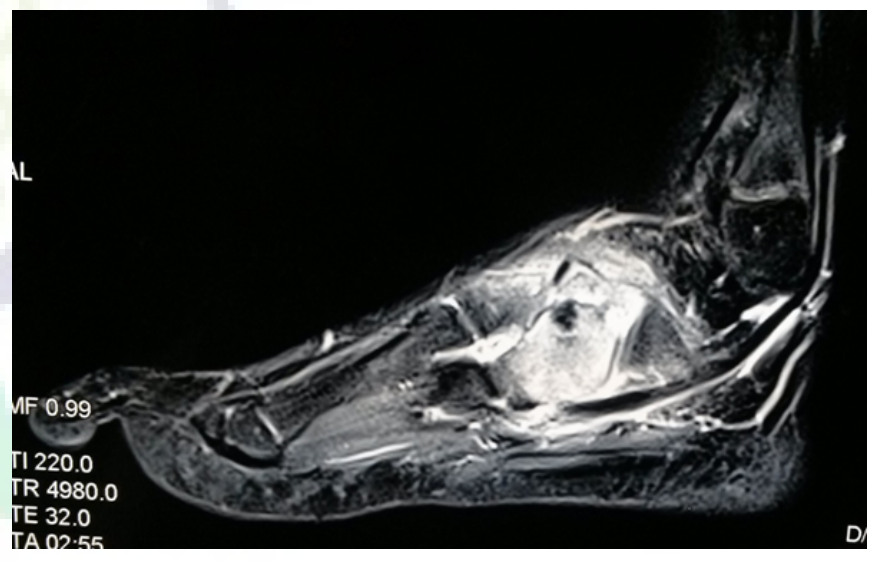

Figure 3: MRI showing diffuse oedema in the medullary cavity of the cuboid bone as well as the surrounding soft tissues. A sub-periosteally located osteoid osteoma nidus was noted in the cuboid bone.

with hyper-dense body with a lucent zone surrounding it raised a clinical suspicion of Osteoid osteoma.

Upon clinical correlation of the history, clinical findings and the radiological findings a diagnosis of osteoid osteoma of the tarsal cuboid was made. The patient was managed conservatively with NSAIDS for 3 weeks and showed significant improvement in her symptoms. At 1 year of follow up visit the patient was asymptomatic without any episode of pain and has no limitation of activities. 


\section{Discussion}

Osteoid osteoma of the foot is a rare benign bone tumour ( $4 \%$ of all cases) and usually affects the tarsal bones. ${ }^{[4,5]}$ It can easily be confused with multiple other conditions like ankle sprain, osteomyelitis, anterior impingement syndrome, stress fractures, chronic tendinitis and arthritis which are more commonly seen. However, a diagnosis of osteoid osteoma should be kept as a differential in cases with chronic foot pain in younger patients, especially when the plain radiographs are unremarkable. Whenever in doubt, a CT scan proves to be beneficial in reaching the diagnosis. $\mathrm{CT}$ is a sensitive imaging technique which can detect upto 0.5 to $1 \mathrm{~cm}$ sized radiolucent nidus, which is the typical feature of osteoid osteoma. A

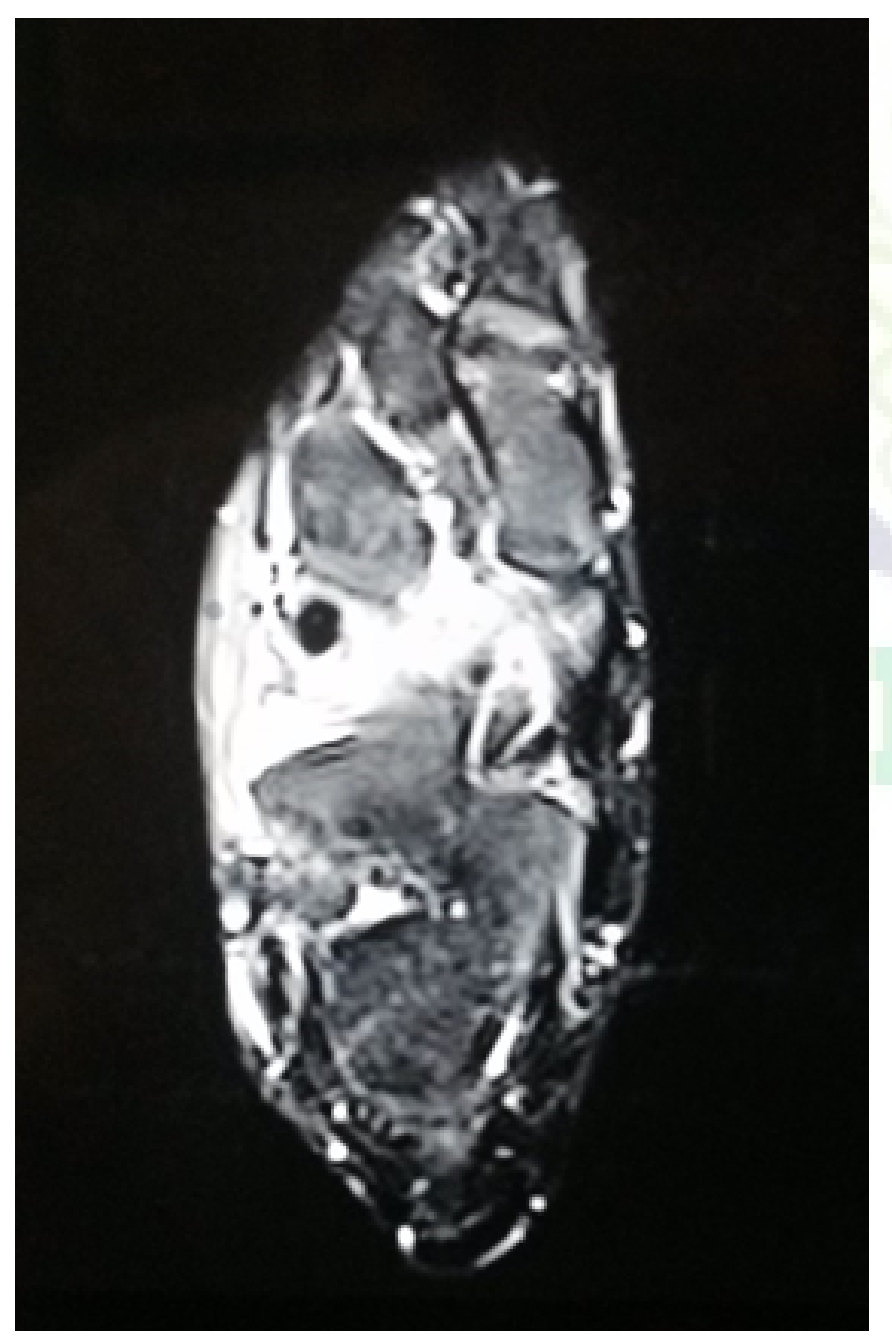

Figure 4: MRI showing diffuse oedema in the medullary cavity of the cuboid bone as well as the surrounding soft tissues. A sub-periosteally located osteoid osteoma nidus was noted in the cuboid bone.

nidus is demonstrated in $85 \%$ of cases. ${ }^{[3]}$ The MRI has been proved less effective in diagnosing osteoid osteoma due to various confounding factors like reporting biases and it also overestimates the medullary and soft tissue oedema which mimics other inflammatory conditions. Radionuclide scan can be used as an additional tool for reaching a diagnosis which shows increased uptake in the late phase.

Persistent pain is the general indication of treatment in osteoid osteoma. However, it can be treated conservatively with prolonged used of NSAIDS. ${ }^{[6]}$ Trial of NSAIDS is worth considering in many cases before sorting to more invasive procedure, especially when the site of the lesion is less accessible. Surgical intervention becomes the treatment of choice in a case with increasing pain which is not responding to the standard trial of NSAIDS. The main purpose of surgical intervention is to remove the nidus which is crucial for pain relief. ${ }^{[3,4]}$ Various other treatment options include, percutaneous resection, ethanol injection, laser photocoagulation, radiofrequency ablation, en-block resection etc. Surgical intervention has more complications and is more costly as compared to percutaneous procedures and ethanol injection, hence reserved for only special cases. Percutaneous resection and ethanol injection are not suitable for the lesions in the foot due to the larger size of the needle, ${ }^{[1]}$ hence radiofrequency ablation is the treatment of choice in osteoid osteoma of foot. ${ }^{[7,8]}$

\section{Conclusion}

In conclusion, osteoid osteoma is not a very common tumour of foot but it should be included in the differentials of chronic foot pain in young adults and children. CT is the investigation of choice in the diagnosis of osteoid osteoma, however a definitive diagnosis should be made based on the histological confirmation. When it comes to the treatment of osteoid osteoma, a conservative management is worth a try before resorting to the more invasive surgical procedures.

\section{References}

1. Corroller TL, Champsaur P. Osteoid Osteoma of the Midfoot: Percutaneous Radiofrequency Treatment in 2 Cases. J Foot Ankle Surg. 2011;50(6):754-757. Available from: https://dx. doi.org/10.1053/j.jfas.2010.12.010.

2. Houdek MT, Wenger DE, Sherman CE, Turner NS. Osteoid osteomas of the foot and ankle: a study of patients over a 20-year period. Am J Orthop. 2014;43(12):552-558.

3. Lee EH, Shafi M, Hui JH. Osteoid osteoma: a current review. J Pediatr Orthop. 2006;26(5):695-700. Available from: https: //doi.org/10.1097/01.bpo.0000233807.80046.7c.

4. Gürkan V, Orhun H, Bülbül M, Kayahan S. Osteoid osteoma of the cuboid bone: a rare cause of foot pain. Acta Orthop Traumatol Turc. 2011;45(1):66-75. Available from: https://doi. org/10.3944/aott.2011.2249. 
5. Shereff MJ, Cullivan WT, Johnson KA. Osteoid-osteoma of the foot. J Bone Joint Surg. 1983;65(5):638-641. Available from: https://dx.doi.org/10.2106/00004623-198365050-00009.

6. Symeonidis PD, Marougiannis D, Chrysoglou G, Christoforidis J. Osteoid Osteoma of the Posterior Talar Dome. J Foot Ankle Surg. 2011;50(3):350-353. Available from: https://dx.doi.org/ 10.1053/j.jfas.2011.01.007.

7. de Ga K, Bateni C, Darrow M, McGahan J, Randall RL, Chen D. Polyostotic osteoid osteoma: A case report. Radiology. 2020;15(4):411-415. Available from: https://dx.doi.org/10. 1016/j.radcr.2020.01.012.

8. Chakraverty J, Al-Mokhtar N, James SL. Osteoid Osteoma of the Cuboid Managed by Percutaneous Radiofrequency Ablation. J Foot Ankle Surg. 2014;53(2):212-215. Available from: https: //dx.doi.org/10.1053/j.jfas.2013.12.003.
Copyright: (C) the author(s), 2020. It is an open-access article distributed under the terms of the Creative Commons Attribution License (CC BY 4.0), which permits authors to retain ownership of the copyright for their content, and allow anyone to download, reuse, reprint, modify, distribute and/or copy the content as long as the original authors and source are cited.

How to cite this article: Chaudhary S, Abdusamad V, Verma A, Garg V, Siddharth RK, Singh V. Osteoid Osteoma of Cuboid Bone- A Rare Cause of Chronic Foot Pain in Childhood -A Case Report. Asian J. Med. Res. 2020;9(4):1-4.

DOI: dx.doi.org/10.47009/ajmr.2020.9.4.OR1

Source of Support: Nil, Conflict of Interest: None declared. 